\title{
Penggunaan Bosoon dan Herba bagi Merawat Sakit Perut dalam Masyarakat Bajau Sama' di Daerah Tuaran, Sabah The Use of Bosoon and Herbs for Treating Stomach Ache in the Bajau Sama' Community of the Tuaran District, Sabah
}

\author{
${ }^{1}$ SABRAN BIN KIBONG \\ ${ }^{2}$ ASMIATY AMAT \\ ${ }^{3}$ LOKMAN ABD SAMAD \\ ${ }^{1 \ll 3}$ Fakulti Kemanusiaan, Seni dan Warisan $/{ }^{2}$ Pusat Penataran Ilmu dan Bahasa, \\ Universiti Malaysia Sabah, Jalan UMS, 88400 Kota Kinabalu. \\ 'boobp@rocketmail.com,2adajiwa@gmail.com,.3lokns@yahoo.com \\ Diterima: 10 Jun 2017 / Dibaiki: 31 September 2017
}

\begin{abstract}
Abstrak Etnik Bajau Sama' yang ramai tinggal di bahagian pantai barat Sabah khususnya di daerah Tuaran memiliki kaedah perubatan tradisional yang diwarisi dari generasi ke generasi. Kajian lapangan dilakukan di tiga lokasi daerah Tuaran, iaitu Kampung Sungai Damit, Kampung Suang Perumahan, Mengkabong dan Kampung Tembilok, Mengkabong. Artikel ini bertujuan untuk meneliti tatacara perubatan tradisi etnik Bajau Sama' dengan menumpukan kepada bosoon atau mantera dan penggunaan herba dalam merawat sakit perut. Kedua, makalah bertujuan untuk meninjau sama ada amalan tradisi ini dipengaruhi oleh masyarakat Bajau di dalam kampung yang berbeza atau tidak berdasarkan jenis penyakit yang dihidapi pesakit. Konsep folk medicine atau folk belief digunakan sebagai kerangka konsep untuk melihat tatacara dan kaedah perubatan tradisi etnik ini. Amalan perubatan ini hanya dilakukan oleh golongan tua kerana sebahagian besar generasi muda tidak tahu tentang amalan tradisi ini. Oleh itu, kajian ini secara tidak langsung memaparkan kepakaran etnik Bajau Sama' dalam amalan perubatan tradisi dan membuktikan kearifan tempatan etnik peribumi Sabah serta menjadi tatapan umum masyarakat akan datang.
\end{abstract}

Kata kunci: Bajau, Tuaran, perubatan tradisi, bosoon, herba, penyakit.

Abstract The Bajau Sama'ethnic, who lives along the West Coast of Sabah especially in Tuaran district, inherits the traditional medicinal practice from generation to generation. Field research was conducted in three different locations in Tuaran district, which are Kampung Sungai Damit Tuaran, Kampung Suang Perumahan, Mengkabong and Kampung Tembilok, 
Mengkabong. This paper aims to examine the traditional medicine of the Bajau Sama' by focusing on the bosoon or mantra and the usage of herbs in treating stomach ache. Secondly, it observes whether the traditional practice is influenced by the Bajau community in different regions based on the patient's illness. The folk medicine or folk belief concept is used as the conceptual framework to observe the procedures and methods of the traditional medicinal practices of the ethnic. The traditional medicinal practice is only done by the older generation as the young generation is not exposed to such practice. Therefore, this research shows the expertise of the Bajau Sama' ethnic in traditional medicinal practice and proves the capability of local wisdom of Sabah's indigenous ethnic. This paper also serves as a reference for the future generations.

Keywords: Bajau, Tuaran, traditional medicine, bosoon, herbs, disease.

\section{PENDAHULUAN}

Bosoon dikenali sebagai mantera oleh masyarakat Bajau Sama' di daerah Tuaran. Dari segi etimologi, kata mantera berasal daripada bahasa Sanskrit, iaitu mantra, manir atau matar yang mempunyai kaitan rapat dengan kitab suci Hindu yang melibatkan kekudusan dan kuasa magis (Haron Daud, 2009: 2). Dalam amalan perubatan tradisi masyarakat Bajau Sama' Tuaran, mereka menjadikan bosoon sebagai ungkapan yang perlu digunakan dalam mengendalikan sebarang tatacara perubatan tradisi mereka. Penggunaan bosoon tidak hanya terhad kepada amalan perubatan, malah bosoon turut berfungsi sebagai alat untuk melancarkan urusan harian dalam kegiatan sosioekonomi dan berperanan besar sebagai pakaian diri bagi tujuan penunduk, pengasih, pelindung, dan memagar diri daripada sebarang marabahaya. Seseorang pengamal perubatan tradisi dalam kelompok masyarakat Bajau Sama' Tuaran dikenali sebagai tabit. Tabit akan menggunakan bosoon dan mempunyai gelaran tertentu seperti 'jomo pandai', 'jomo ngerati', 'jomo ngurut', dukun, 'tukang manak' atau pengguling (bidan) yang dianggap penting kerana masih bergiat aktif dalam perubatan secara tradisional. Meskipun kini perubatan cara moden menjadi pilihan, masyarakat, perubatan secara tradisional tidak pula dikesampingkan. 
Menurut Haron (2009), mantera tidak boleh diubah dan mantera tidak boleh diajarkan kepada orang yang belum berhak kerana pelanggaran atau penyalahgunaannya dipercayai akan mendatangkan kesan buruk. Oleh itu, kebanyakan pengamal tradisional yang mempunyai bosoon tidak mewariskan bosoon kepada sembarangan orang dan sebahagian besar hanya mewariskan bosoon kepada mereka yang mempunyai hubungan keluarga sahaja. Secara tidak langsung, hal ini menggambarkan bahawa sifat bosoon yang mengandungi kuasa luar biasa perlu dipelihara dengan sebaiknya agar tidak digunakan dengan semberono dan tidak pula memudaratkan pemberi bosoon dan pengamal bosoon. Begitu juga dengan pendapat Heru (2007) yang menyifatkan mantera merupakan suatu doa sakral kesukuan yang mengandungi magis dan berkuasa ghaib. Bagi masyarakat Bajau Sama' Tuaran, penggunaan bosoon dan herba bagi tujuan perubatan sangat sinonim dalam kehidupan mereka. Hubungan kedua-dua elemen ini dipercayai mampu memberikan manfaat kesembuhan dan sebagai tatacara yang penting kepada pesakit dalam proses perubatan tradisi mereka. Sesetengah penyakit biasa yang dirawat dengan menggunakan kaedah tradisional hanya memerlukan herba sematamata tanpa menggunakan sebarang bosoon. Seperti mana masyarakat lain di Nusantara, mereka turut mempunyai mantera yang hampir sama fungsi dengan bosoon. Keunikan bosoon dan penggunaan herba dalam masyarakat Bajau Sama' Tuaran masih mengekalkan nilai tradisinya menambahkan kajian terhadap amalan tradisi. Ia perlu sebagai langkah pemuliharaan dan melestarikan khazanah warisan jati diri bangsa Bajau Sama' Tuaran agar tidak lenyap dalam arus kemodenan.

Sejajar dengan kajian lepas, objektif kajian ini bertujuan untuk meneliti keunikan dan keistimewaan bosoon yang dimiliki oleh masyarakat Bajau Sama' di daerah Tuaran terutama yang berkaitan dengan mantera dan penggunaan herba dalam merawat penyakit. Sejajar dengan itu, objektif kedua kajian ini bertujuan meninjau sama ada amalan tradisi ini saling dipengaruhi oleh masyarakat Bajau di dalam kampung yang berbeza atau tidak. Persoalan kajian merujuk kepada keunikan dan keistimewaan perubatan tradisi atau mantera ini bagi masyarakat Bajau dengan membandingkan tiga kampung yang berbeza dalam satu daerah. 
Lokasi kajian dalam penyelidikan ini tertumpu di sekitar daerah Tuaran yang terletak di antara laluan Kota Kinabalu dengan Kota Belud. Daerah Tuaran terbahagi kepada tiga bahagian kecil, iaitu bahagian Tamparuli, Sulaman dan Kiulu (Masters Indeks Daftar pemilih terkini sehingga ST3/2016 yang dikemas kini sehingga 30 September 2016). Tiga buah kampung menjadi lokasi kajian, iaitu Kampung Sungai Damit, Tuaran, Kampung Suang Perumahan, Mengkabong, Tuaran dan Kampung Tembiluk, Mengkabong, Tuaran. Beberapa kriteria diambil kira berkenaan pemilihan lokasi kajian. Pertama, kawasan kampung didiami oleh majoriti masyarakat Bajau. Kedua, kampung yang terpilih mempunyai pengamal perubatan tradisional dalam kalangan masyarakat Bajau Sama' yang mahir menggunakan mantera dan kaedah perubatan berasaskan tumbuh-tumbuhan.

Beberapa orang informan terdiri daripada golongan pengamal perubatan tradisi telah ditemu bual bagi mendapatkan bosoon yang digunakan dalam pengubatan tradisonal. Sebilangan besar pengamal terdiri daripada golongan tua yang bekerja sebagai petani, nelayan, pesara pencen, pemandu bas dan suri rumah sepenuh masa. Golongan pengamal tradisional sangat besar pengaruhnya dalam kalangan masyarakat Bajau di daerah Tuaran. Setiap pengamal ini memiliki kepakaran dan kemahiran dalam kaedah merawat pelbagai jenis penyakit. Setiap daripada mereka ini dianggap orang yang arif dalam mengenal jenis penyakit dan kaedah rawatan untuk membantu pesakit. Seramai 15 orang informan telah ditemu bual terdiri daripada masyarakat Bajau Sama' yang masih mengamalkan perubatan tradisi sehingga hari ini.

Rata-rata pesakit yang ingin mendapatkan rawatan tidak terikat kepada status sosial mereka asalkan penyakit mereka dapat disembuhkan. Seseorang individu yang menyedari dirinya dilanda penyakit secara tidak langsung akan berusaha untuk mencari penawar bagi menyembuhkannya. Kepercayaan masyarakat Bajau Sama' Tuaran dalam perubatan tradisi di samping tempat mendapatkan perubatan yang hampir dengan tempat tinggal mereka menyebabkan mereka memilih perubatan tradisi bagi merawat sebarang jenis penyakit. Bukan itu sahaja, kebanyakan perubatan tradisi ini tidak memerlukan kos dan perbelanjaan yang banyak. Seperti yang kita ketahui, penyakit yang dirawat dengan kaedah rawatan moden melibatkan 
prosedur yang lebih kompleks dan sesetengah pesakit terpaksa menjalani rawatan pembedahan bagi mengesan penyakit yang tidak dapat dikesan dengan kaedah rawatan moden. Justeru, di sinilah perubatan tradisional akan dipraktikkan sebagai ikhtiar bagi menangani masalah ini.

Kaedah kajian yang djalankan adalah kerja lapangan yang melibatkan temu bual secara individu, berkumpulan dan pemerhatian langsung. Bagi kaedah temu bual secara individu, pengkaji menjalankan temu bual secara langsung di rumah informan untuk mendapatkan maklumat berkenaan perubatan tradisi yang dilakukan oleh setiap pengamal perubatan tradisi, sama ada menggunakan mantera ataupun menggunakan tumbuhan atau kedua-dua kaedah dalam merawat penyakit. Dalam kaedah temu bual berkelompok pula, pengkaji menemu bual informan secara serentak untuk mendapatkan maklumat berkenaan jenis perubatan tradisi yang melibatkan pengamal dan pesakit-pesakit yang pernah menjalankan rawatan bersama dengan pengamal terpilih.

Selain itu, pengkaji juga melakukan pemerhatian secara langsung dengan kaedah melibatkan diri bersama pengamal perubatan tradisi ketika merawat dan menyediakan ubat-ubat tertentu bagi menyembuhkan penyakit seorang pesakit. Melalui itu, pengkaji dapat melihat sendiri bagaimana kaedah dan proses membuat ubat-ubatan yang berasaskan tumbuh-tumbuhan dalam merawat sebarang bentuk penyakit. Justeru, pengkaji dapat melihat sendiri jenis dan bahagian tumbuhan yang diperlukan bagi penghasilan ubat yang lebih berkesan oleh setiap pengamal perubatan tradisi.

Kajian terhadap penggunaan mantera etnik di Sabah pernah dikaji oleh beberapa orang pengkaji seperti Hanafi Husin (2003, 2005) dan Minah Sintian (2012). Kedua-duanya membincangkan rinait etnik Kadazandusun di Sabah. Bagi mantera etnik Murut Tahol, ia dikaji oleh Julius Kulip (2003) dan Normadiah Nasir (2015), sementara bagi masyarakat Bajau di Sabah, kajian dijalankan oleh Haron Daud (2004), Saidatul Nornis (1999) dan Jasman Bandar (2015) yang dibuat di beberapa daerah berasingan.

Kajian terawal mantera Bajau Tuaran pernah dilakukan oleh Haron Daud (2004) dengan memperincikan jumlah mantera di Tuaran 
sebanyak 35 jenis mantera. Namun begitu, penelitian beliau hanya mendokumentasikan bentuk dan jenis mantera tanpa menjelaskan intipati maksud mantera, sama ada dari segi tatacara dan kaedah menggunakan mantera secara khusus dalam kalangan masyarakat Bajau. Penelitian beliau turut tidak menjelaskan lokaliti kajian secara jelas. Oleh itu, pada pandangan pengkaji, kajian terhadap mantera Bajau Sama' perlu dilakukan bagi menambah salah satu kajian lengkap khususnya berkenaan mantera Bajau Sama' di daerah Tuaran.

Tulisan Saidatul Nornis Hj Mahali dalam Mantera: Satu Penelitian Awal di kalangan Petani Bajau (1999) bersifat kajian antropologi dan lingusitik yang mencatatkan peranan mantera dalam kalangan masyarakat petani Bajau di Kota Belud dalam kegiatan penanaman padi. Masyarakat Bajau percaya bahawa sebelum melakukan aktiviti penanaman padi, mereka perlu mengadakan upacara memuji semangat padi agar tanaman yang dihasilkan lebih subur. Saidatul (1999) turut menyenaraikan beberapa versi mantera dalam upacara pemujaan semangat padi yang mengandungi perkataan "Bismillahirahmanirahim" di awal mantera. Hal ini membuktikan bahawa pengaruh agama Islam telah meresap ke dalam bait-bait mantera Bajau di Kota Belud.

Kajian Jasman Bandar dalam tesis sarjana bertajuk Konsep Mantera dalam Masyarakat Bajau Pitas, Sabah (2015) meneliti fungsi mantera dalam kalangan masyarakat Bajau dengan menggunakan pendekatan fenomenalogi. Jasman (2015) menyifatkan mantera sebagai 'senjata' untuk menyelamatkan diri daripada gangguan makhluk halus, manusia, haiwan buas, penyakit dan alat melancarkan urusan seharian. Jika diteliti dalam konteks kajian tersebut, beliau telah menyenaraikan sebanyak 50 mantera mengikut kategori dan fungsi. Dalam penelitian beliau, terdapat juga mantera pengubatan dalam amalan tradisi, tetapi tidak membincangkan dengan lengkap kaedah dan tatacara rawatan serta penggunaan herba yang dibuat dalam sebarang upacara merawat penyakit.

Berdasarkan kajian lepas, ternyata mantera Bajau di daerah Tuaran perlu dikaji secara mendalam dan lebih terperinci atas dasar daerah Tuaran juga merupakan kawasan tumpuan masyarakat Bajau Sama' kedua terbesar 
selepas daerah Kota Belud. Bukan itu sahaja, mantera dalam perubatan tradisi etnik Bajau Sama' Tuaran ini juga memiliki keistimewaan yang tersendiri dengan mengambil kira fungsi mantera dan herba yang mampu menyembuhkan sebarang jenis penyakit. Namun, kajian ini memfokuskan kepada bosoon dan herba untuk merawat sakit perut.

\section{KONSEP PERUBATAN TRADISI BAJAU SAMA' TUARAN}

Kepercayaan masyarakat terhadap perubatan tradisonal folk belief atau folk medicine diwarisi secara turun-temurun sejak zaman nenek moyang mereka. Menurut Felipe (2003: 6), folk belief atau folk medicine merujuk kepada kepercayaan tradisional masyarakat. Menurut beliau, “...the phrase folk medicine has reference to the body of traditional belief and practices related to health and illness in the community."

Kenyataan beliau itu menggambarkan bahawa kepercayaan tradisi itu merangkumi kepercayaan terhadap perubatan tradisi dan amalan penjagaan kesihatan diri. Taib Osman (1988: 107) menyatakan kepercayaan tradisional atau folk belief orang Melayu telah bercampur aduk antara unsur kepercayaan yang diwarisi sejak zaman berzaman dan sesetengah perlakuan ditegah oleh agama. Perubatan tradisional biasanya sering dikaitkan dengan peranan golongan pengamal perubatan tradisi yang memiliki kepakaran dan kemahiran dalam merawat dan menyelesaikan sebarang masalah yang dialami oleh sebahagian masyarakat sekitarnya. Memandangkan masyarakat Bajau Sama' Tuaran masih tinggal di kawasan luar bandar dan perkhidmatan klinik desa yang agak jauh, khidmat bidan yang masih wujud di kawasan petempatan masyarakat ini menyebabkan amalan perubatan tradisi masih mendapat tempat dalam kalangan masyarakatnya. Salah satu bahan terpenting dalam konteks folk medicine adalah tumbuhan atau herba. Sifatnya yang mudah diperoleh dan kawasan petempatan masyarakat Bajau Sama' yang masih dikelilingi oleh kawasan hutan dan paya bakau menyebabkan sejak dari dulu etnik Bajau Sama' sangat yakin dengan tumbuhan dan herba yang mampu menyembuhkan penyakit. Dalam konteks perubatan tradisi, kegunaan herba memang telah lama menjadi amalan dalam setiap bangsa yang terdiri daripada pelbagai kelompok kaum dan juga 
mewarisi amalan perubatan yang tersendiri (Faisal \& Nurul Wahidah, 2012: 153). Kebanyakan tumbuhan yang diambil daripada hutan akan ditanam berhampiran dengan rumah mereka bagi memudahkan proses menyediakan bahan untuk menghasilkan pelbagai jenis ubat.

Menurut Zainah (88 tahun), kepercayaan beliau terhadap tumbuhtumbuhan hutan menyebabkan sehingga kini beliau masih lagi bergiat aktif dalam pekerjaan sebagai tabit. Menurut Saidah (58 tahun) pula, penyediaan ubat-ubatan tradisi yang ringkas dan berkesan telah menyebabkan pengubatan tradisi Bajau Sama' Tuaran ini memiliki keistimewaan yang tersendiri, terutama dalam tatacara rawatan penyakit yang disebabkan angin mendelout atau angin laut yang masuk ke dalam tubuh badan seseorang serta penyakit-penyakit yang berkaitan dengan gangguan makhluk halus. Menurut Liadin (58 tahun), kepercayaan orang Bajau terhadap semangat dalam ruang lingkup kehidupan mereka sudah sebati dan petua pantang larang harus dihormati. Menurutnya lagi, semasa pergi ke hutan untuk mengambil ubat, seseorang tabit tersebut perlu memberi salam kepada penghuni hutan yang tidak dapat dilihat oleh pandangan mata kasar manusia. Hal ini bertujuan agar mahkluk yang berada di dalam hutan menyedari kehadiran manusia di tempat mereka dan mengelakkan daripada hantu seperti kokok (embok labi) yang datang mengganggu dan menyesatkan manusia yang melanggar petua pantang larang. Oleh itu, tidak hairanlah bahawa bosoon memiliki peranan yang luas baik dalam aspek perubatan dan petua orang Bajau sebagaimana konsep folk belief yang diwarisi sejak dulu.

Perkataan bismillahirahmanirahim dan laillahaillah muhamadurasulullah pada bahagian awal dan akhir bosoon membuktikan bahawa mantera etnik Bajau Sama' Tuaran telah dipengaruhi oleh agama Islam. Namun, sebahagian besar bosoon yang diungkapkan masih mengekalkan nilai animisme dalam mencapai konsep tradisi yang masih wujud sehingga kini. Bosoon memiliki pelbagai bentuk dan fungsi yang sangat besar terhadap masyarakat Bajau Sama' Tuaran. 


\section{PENGGUNAAN BOSOON DAN HERBA DALAM RAWATAN 'PEDIH BETONG'}

Perubatan Melayu tradisional ditakrifkan melalui dua takrif, yang mana 'perubatan' berasal daripada perkataan ubat yang membawa maksud sesuatu benda yang digunakan untuk menyembuhkan penyakit atau menyihatkan badan, sama ada dengan cara dimakan atau disapu (Faisal Ahmad Faisal Abdul Hamid, Nurul Wahidah binti Fauzi, 2012: 149). Sehubungan itu, konsep kepercayaan perubatan tradisi etnik Bajau Sama' khususnya di daerah Tuaran menggunakan bosoon sebagai alat untuk memperhubungkan segala penyakit kepada konsep penyembuhan. 'Pedih betong' atau sakit perut merupakan salah satu penyakit yang biasa diubati oleh tabit.

Penyakit 'pedih betong' ini juga dikategorikan kepada masalah angin yang mengganggu bahagian perut seorang pesakit. Menurut Saidah (58 tahun), masalah 'pedih betong' ini sering berlaku kepada gologan ibu yang sedang mengandung, orang dewasa dan bayi. Menurutnya lagi, 'angin atai benono' atau 'angin mendelout' akan memasuki perut ibu yang mengandung. Hal ini menyebabkan perut ibu sakit kerana sejuk. Sebagai seorang tabit, beliau akan menggunakan bosoon dan tumbuh-tumbuhan yang bersifat panas dalam merawat penyakit ini yang mana dipercayai mampu membuang segala jenis angin. Kegunaan herba memang telah lama menjadi amalan dalam setiap bangsa yang terdiri daripada berbagai kelompok kaum dan juga mewarisi amalan perubatan yang tersendiri (Faisal Ahmad Faisal Abdul Hamid, Nurul Wahidah binti Fauzi, 2012: 153).

Masyarakat Bajau Sama' Tuaran turut memanfaatkan herba-herba di sekeliling mereka untuk dijadikan penawar menyembuhkan 'pedih betong'. Herba-herba tersebut diyakini secara warisan dari zaman nenek moyang masyarakatnya. Menurut Temiah (58 tahun), herba-herba terpilih yang digunakan dalam penghasilan ubat 'pedih betong' hanya menggunakan kaedah merebus, menumbuk, membakar dan menjemur. Bagi golongan tabit yang merawat perempuan mengandung, mereka akan menggunakan beberapa helai daun kolimpopo (lihat Foto 1) yang dipercayai mampu menghilangkan penyakit angin dan menghindarkan pesakit daripada gangguan mahkluk halus. Menurut cerita orang tua-tua, daun ini 
biasanya tumbuh di dalam hutan dan disebabkan banyak tumbuhan lain gemar menumpang di bahagian akar sehingga ke batang pokok tersebut. Masyarakat Bajau Sama' percaya bahawa pokok tersebut mempunyai banyak khasiat yang mampu membantu manusia.



FOTO 1 Daun kolimpopo (daun hutan yang dipercayai mempunyai semangat halus)

Sumber: Kerja lapangan

Dalam konteks rawatan tradisi masyarakat Bajau Sama' Tuaran, amalan meminum air rebusan daun kolimpopo dan pucuk daun lada merupakan ramuan ubat untuk membuang angin sekali gus mencairkan ketulan darah nifas perempuan lepas bersalin yang berada di dalam pangkal rahim. Pengamalan meminum air rebusan ini diambil dalam keadaan berkala, iaitu dua ketiga kali dalam seminggu sahaja. Semasa merawat penyakit, bosoon perlu digunakan. Berikut diturunkan beberapa bait bosoon bagi merawat 'pedih betong:'

Bismillahirahmanirrahim, Aku tahu asal mulamu jadi, anginku sampang laut, daun gulung-gulung, turun si raja bisa naik si raja tawar,

bukan aku ampunya tawar, Nabi sulaiman punya tawar, berkat doa laillahaillah Muhammadarusulullah. 
Terjemahan bebas: Dengan nama Allah Yang Pengasih dan Maha Penyayang, aku tahu asal kejadian engkau angin, angin kubenteng asal dari laut, sifat angin berpusing, hilangkan segala kesakitan, sembuhkanlah segala penyakit, bukan aku kepunyaan tawar tetapi Nabi Sulaiman punya tawar berkat doa mujarablah engkau, berkat daripada tiada Tuhan yang disembah melainkan Allah dan Nabi Muhammad itu pesuruh Allah.

\section{Sumber: Saidah binti Remis}

Mantera tidak boleh lari dari ucapan untuk melahirkan kuasa sakti. Mantera digubah dengan susunan bahasa khusus yang tidak dapat difahami maksudnya oleh orang kebanyakan atau orang yang tidak mempelajari ilmu ghaib atau ilmu perdukunan (Saidatul, 1999: 55). Menurut Saidah (58 tahun), penggunaan bosoon ini dikatakan lebih kepada tingkah laku untuk memuji atau menyeru angin yang mengganggu perut pesakit dengan cara menyatakan pada asal kejadian angin yang datang dari laut. Perkataan sampang bermaksud benteng atau memagari. Ia membuktikan keistimewaan penggunaan bosoon ini bersifat menghindarkan atau menghalau angin jahat daripada terus mengganggu pesakit. Golongan tabit percaya sesebuah penyakit yang disebabkan oleh angin dapat dirawat dengan memanggil semangat angin tersebut. Menurut Abd Adis ( 78 tahun), perkara yang paling penting dalam bosoon untuk rawatan ini adalah ungkapan 'aku tahu asal mulamu' yang cukup membawa makna kata seruan untuk menyatakan sifat kejadian kepada angin yang dipercayai sebahagian daripada salah satu unsur kejadian manusia iaitu api, air, angin dan tanah. Masyarakat Bajau Sama' Tuaran percaya angin turut mempunyai sifat seperti manusia sekiranya diseru dengan baik. Angin tersebut akan menghindarkan diri daripada melakukan sebarang malapetaka kepada manusia. Sekiranya angin tersebut dikutuk dengan kata cacian atau perkataan yang kesat, maka akan terjadilah angin ribut dan angin puting beliung yang bakal meranapkan segalanya. Jelaslah bahawa konsep hubungan manusia dan alam begitu erat. Selaras dengan keperluan untuk menjaga dan melindungi diri serta keluarga daripada sebarang bencana yang dihasilkan oleh alam (Saidatul, 1999: 60).

Bagi melihat tatacara merawat penyakit ini, tabit (bidan) akan memegang bahagian perut pesakit sambil menepuk-nepuk perut pesakit dengan lembut. Perkara ini bertujuan untuk memastikan kesakitan 
disebabkan masalah daripada penyakit selain yang berpunca daripada angin. Jika penyakit tersebut berpunca daripada angin, maka perut yang ditepuk akan menghasilkan bunyi. Selain itu, kemunculan urat-urat tertentu di bahagian perut turut menunjukkan pesakit yang menghidapi 'pedih betong' ini diganggu oleh angin jahat yang perlu diseru akan asal kejadiannya dengan melafazkan bosoon di atas. Tabit akan meniup perut ibu mengandung mengikut arah lawan jam. Sepanjang proses mengurut juga, bidan akan menggunakan selan tenanak (minyak yang telah ditanak) sambil melurutkan perut pesakit dari bahagian atas sehingga ke bahagian bawah perut.

Setelah proses mengurut dilakukan, bidan akan menyediakan sejenis air rebusan campuran daripada daun kolimpopo dan daun pucuk lada muda seperti yang telah dijelaskan sebelum ini. Tatacara kaedah rawatan menggunakan tumbuh-tumbuhan dan herba ini kemungkinan besar merupakan sebahagian daripada pengaruh masyarakat Melayu terdahulu yang dapat dibuktikan dalam penulisan kebanyakan daripada cara rawatan. Bentuk petua dan cara agak ringkas, di mana herba-herba hanya perlu dimakan mentah ataupun dilumurkan pada anggota tubuh. Pendapat ini turut disokong dengan rawatan etnik peribumi Murut di Sabah yang dibincangkan oleh Normadiah dan Low (2015) yang menyatakan bahawa pengetahuan berkenaan herba dan tumbuhan yang dibuat ubat diperoleh melalui ajaran orang terdahulu, pengalaman sendiri serta kepekaan mereka terhadap tumbuh-tumbuhan di sekeliling. Oleh itu, jelaslah bahawa konsep folk medicine dalam kalangan etnik peribumi Sabah masih belum terhakis meskipun rawatan moden adalah tatacara terbaik bagi mereka yang mampu untuk membiayai kos rawatan yang agak tinggi.

Di peringkat bayi pula, rawatan 'pedih betong' dilakukan oleh tabit (bidan atau tukang manak). Tukang manak akan melakukan sampang sawan pedih betong atau memasang pagar untuk mengelakkan angin yang datang dari laut mengganggu perut bayi. Berikut adalah bait bosoon ke atas perut bayi: 


\author{
Bismilla \\ Sampang laut bergulung \\ Daun kayu \\ Panji (uri) indah terbang \\ Sampang laut aku tahu \\ Asal mula mulamu jadi \\ Angin laut, berkat laillahaillah muhamadurasulullah.
}

Terjemahan bebas: Dengan nama Allah Yang Maha Pengasih lagi Maha Penyayang, aku benteng angin asal dari angin laut, sifat angin yang menerbangkan daun dan kayu, panji (bendera) dikibarkan, aku sampang (pagar) angin laut, aku tahu asal mula mu angin datang daripada laut, berkat tiada Tuhan yang disembah melainkan Allah dan aku bersaksi bahawa Nabi Muhammad itu pesuruh-Nya.

\title{
Sumber: Bidan Senah
}

Bahan yang diperlukan dalam menghasilkan ubat sakit perut kepada bayi adalah daun sirih, beberapa hirisan biji pinang, apo (kapur), dan sigup (tembakau kering). Kesemua bahan dilumatkan ke dalam gusu (gobek) dan dikeluarkan bagi tujuan penyaringan (lihat Foto 2). Setelah itu, tukang manak akan meletakkan bahan yang telah lumat ke bahagian kain bengkung bayi (barut) diiringi dengan lafaz bosoon 'pedih betong' bagi bayi yang belum mencapai usia sebulan dari hari kelahirannya (lihat Foto 3). Menurut Senah (68 tahun), semasa memasang barut terdapat pantang yang perlu dielakkan bagi mengelakkan bayi daripada terus menangis, iaitu bahan sirih yang telah lumat tidak boleh terkena pada bahagian kulit perut bayi kerana dikhuatiri bayi tersebut akan melecur disebabkan sirih memiliki sifat panas dan berangin. Menurut Madil (59 tahun), kulit bayi yang masih lembut tidak perlu didedahkan dengan haba yang terhasil daripada kunyahan sirih tersebut. Kaedah rawatan tradisi ini dipercayai mampu mengeluarkan angin yang sejuk dari bahagian perut bayi, secara tidak langsung mengelakkan bayi terkena penyakit kembung perut yang melampau dan sawan tangis. 


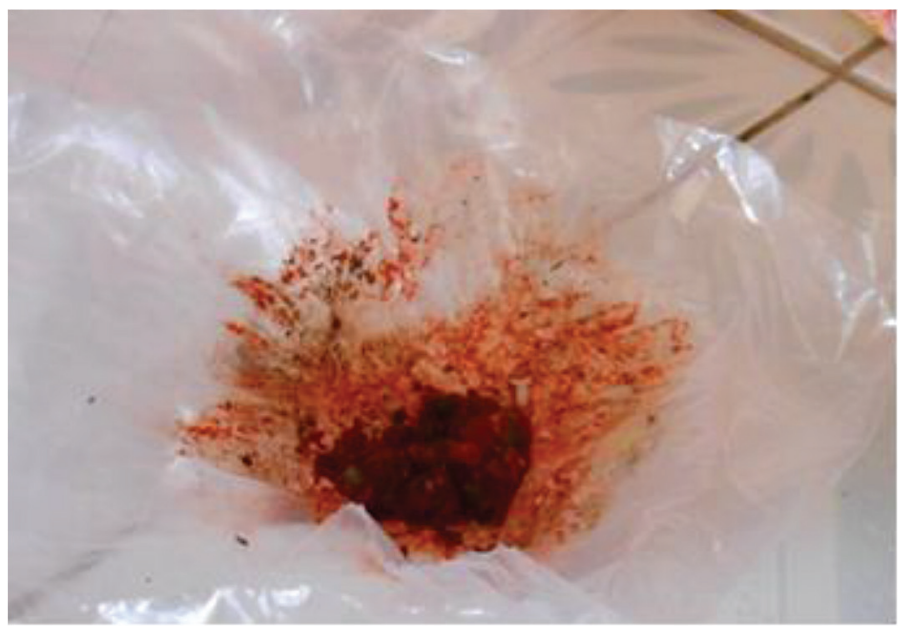

FOTO 2 Bahan sirih yang telah dikunyah oleh tukang manak (bidan) Sumber: Kerja lapangan



FOTO 3 Barut (bengkung bayi) yang dipakaikan pada bahagian perut bayi

Sumber: Kerja lapangan 
Kebiasaannya, rawatan penyakit ke atas bayi dalam konteks pengamal perubatan mempunyai tatacara yang berbeza-beza. Pada hemat pengkaji, rawatan tradisi Bajau Sama' Tuaran mempunyai keunikan yang tersendiri dan kepercayaan mereka terhadap perubatan tradisonal masih dipraktikkan. Buktinya, pelbagai herba tertentu tetap dimanfaat dan dijadikan salah satu kumpulan herba yang mampu dilestarikan sebagai bahan perubatan meskipun segelintir pihak telah menolak keberkesanan rawatan ini kerana kajian secara saintifik belum pernah dilakukan. Namun begitu, amalan dan tatacara yang masih dikekalkan ini membuktikan bahawa konsep folk belief menjadi landasan masyarakat ini dan terus memegang teguh kearifan tempatan mereka. Bukan itu sahaja, kepakaran yang dimiliki ini dipercayai berdasarkan pengalaman masa lampau dan kepekaan terhadap tumbuh-tumbuhan sekelompok masyarakat sehingga membentuk kearifan masyarakat Bajau Sama' di tiga kampung di Tuaran.

Selain itu, salah satu penyakit biasa yang menggunakan bosoon adalah penyakit 'uri kenakan' atau sangat sinonim dikenali sebagai penyakit gastrik. Masalah ini diketahui berpunca daripada masalah pemakanan yang tidak teratur sehingga mengundang kelaparan perut yang melampau. Bagi masyarakat Bajau Sama' Tuaran, penyakit 'uri kenakan' ini dirawat dengan menggunaakan bosoon berserta ubat 'uri kenakan' yang dibuat hasil daripada campuran tumbuh-tumbuhan hutan. Kelewatan waktu makan juga dikhuatiri mengundang penyakit 'dugal', iaitu keradangan pada hulu hati sekali gus pesakit akan mengalami sesak nafas. Salah satu spesies tumbuhan yang mampu menyembuhkan penyakit 'uri kenakan' adalah spesies pisang yang dikenali sebagai pisang kenawar oleh masyarakat Bajau Sama' Tuaran (lihat Foto 4). Konsep folk belief terhadap pisang kenawar baik dari bahagian batang, jantung pisang dan buah pisang tersebut jika dimakan mampu meredakan masalah tersebut. Pisang ini sangat besar manfaatnya dalam sistem penghadaman. Umbut batang pisang kenawar bersama tongkol (jantung pisang kenawar) turut dijadikan sayur bagi membantu penghadaman di dalam perut. 




FOTO 4 Pisang kenawar serba guna yang digunakan dalam merawat penyakit gastrik

Sumber: Kerja lapangan

Menurut Temiah (57 tahun), beliau sering mengambil pisang kenawar untuk dijadikan bahan makanan sampingan bagi merawat dirinya sendiri. Kepercayaan ini diwarisi daripada arwah ibunya yang juga seorang tabit. Khasiat pisang kenawar ini turut dimanfaatkan dalam penghasilan ubat tradisi 'uri kenakan' yang sehingga kini masih digunakan oleh masyarakat Bajau Sama' di daerah Tuaran. Menurut Zainah (88 tahun), beliau menggunakan pisang kenawar sebagai salah satu bahan penting dalam penghasilan ubat 'uri kenakan'. Beberapa jenis tumbuhan hutan akan dipanggang di atas bara api bersama buah pisang kenawar yang telah dikeringkan. Bahan yang telah menjadi ketulan hitam akan ditumbuk halus menjadi debu arang hitam (lihat Foto 5). 


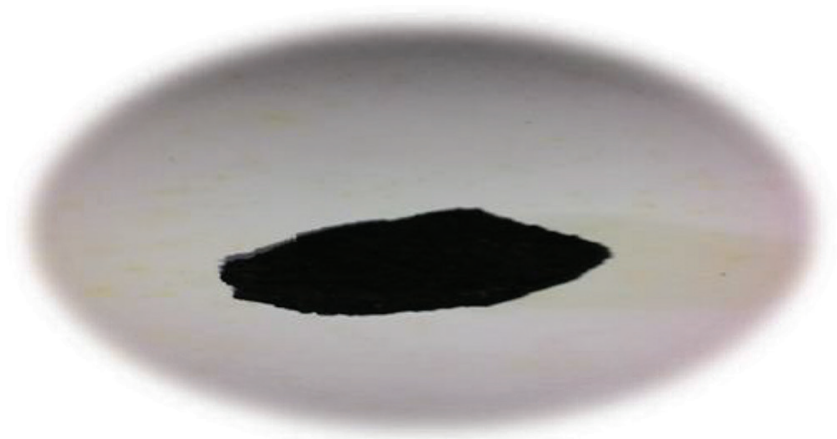

FOTO 5 Ubat 'uri kenakan' dalam keadaan ketulan arang selepas dibakar Sumber: Kerja lapangan

Bahan-bahan yang telah lengkap akan dikumpul dalam satu bekas kosong dan dibakar kesemua sekali. Menurut Zainah (88 tahun), beliau akan memperoleh tumbuh-tumbuhan yang dibuat ubat daripada hutan yang berhampiran. Setelah bahan tersebut dibakar, seterusnya adalah proses menyaring bahan-bahan bagi mengasingkan benda asing ataupun ketulan. Apabila bahan tadi menjadi serbuk, maka ubat tersebut bolehlah digunakan sebagai bahan sapuan pada bahagian kulit atau diminum. Bagi memastikan ubat ini lebih mujarab, 'uri kenakan' dicampur bersama minyak masak agar melekat pada bahagian kulit perut setelah dilumurkan. Dipercayai, bahan-bahan campuran tadi mampu menstabilkan uri pada bahagian perut daripada terus mengembang, sekali gus mampu menyedut angin keluar daripada bahagian perut pesakit. Kawasan yang telah dilumurkan ubat 'uri kenakan' akan menjadi sejuk sehingga memberikan keselesaan pada bahagian perut daripada terus meragam. Semasa melumurkan ubat tadi, bosoon akan dilafazkan bagi memohon belas kasihan 'angin delaut' yang masuk ke dalam badan.

\section{Bismillahirahmanirrahim,}

Tabi-tabi embo,

Embo pandai noos diri nie,

Berai kam ta barang empu bi, Berkat laillahaillah muhamdarasulullah. 
Terjemahan bebas: Dengan nama Allah yang Maha Pengasih lagi Maha Penyayang, jauh-jauh embo (makhluk halus), embo pandai mengubati dirinya, kasihanlah anak cucu engkau, berkat tiada tuhan yang disembah melainkan Allah dan Nabi Muhammaad itu pesuruh-Nya.

Sumber: Zainah binti Alun

Sesetengah penyakit ini dianggap biasa dan rawatan pada peringkat perubatan moden dikesan sebagai masalah gastrik. Namun, bagi masyarakat Bajau Sama' Tuaran, penyakit 'uri kenakan' merupakan penyakit tradisi yang sangat bahaya kerana jika tidak diubati akan menyebabkan seseorang itu hilang selera makan dan lumpuh kerana masyarakat Bajau percaya bahawa makhluk halus atau semangat jahat sudah mula menguasai bahagian perut pesakit tersebut. Bagi golongan perempuan, masalah 'uri peranakan' (pangkal rahim) yang tidak stabil boleh menyebabkan penyakit ini datang menyerang pada bila-bila masa. Bagi golongan lelaki dewasa pula akan mengalami masalah gastrik ini apabila terlewat waktu makan. Oleh itu, tabit akan bertindak sebagai pengamal dalam memastikan segala bentuk perubatan tradisi disediakan dengan sebaiknya.

Penggunaan ayat dalam sesebuah bosoon membuktikan kepercayaan masyarakat Bajau Sama' Tuaran terhadap perubatan tradisi yang diamalkan di tiga kampung sejak berkurun lama memiliki keunikan dan keistimewaan yang tersendiri dalam kewujudan mantera Bajau. Penghasilan mantera yang bertujuan untuk berhubung dengan kuasa ghaib demi keselamatan mereka mengandaikan bahawa kewujudan mantera sama lamanya dengan kewujudan masyarakat itu sendiri (Haron Daun, 2009: 36). Selain keistimewaan itu, konsep kepercayaan perubatan tradisi ini dapat diterjemahkan lagi apabila masyarakat Bajau Sama' Tuaran turut menggunakan amalan makan sirih sebagai salah satu alternatif perubatan tradisional yang mungkin tidak dimiliki oleh masyarakat Bajau di tempat lain. Jika di alam Melayu kita dapat melihat amalan makan sirih sering dijadikan santapan umum kepada tetamu yang datang ke rumah. Ia berbeza dengan etnik Bajau Sama' Tuaran yang mengaplikasikan amalan tradisi kepada alternatif perubatan tradisi, sekali gus membuktikan keberkesanan kepada kepercayaan perubatan tradisi sebagai lambang khazanah warisan. 


\section{KESIMPULAN}

Hasil dapatan mendapati bahawa ketiga-tiga kampung meyakini bahawa semangat angin yang dipercayai mengandungi semangat jahat yang masuk ke dalam bahagian tubuh badan seseorang boleh mengakibatkan masalah 'pedih betong' atau sakit perut daripada pelbagai peringkat umur. Rawatan sakit perut yang dikategorikan kepada ibu mengandung, bayi dan orang biasa jelas menggambarkan bahawa peranan bosoon dan herba masih diamalkan di tiga buah kampung yang dinyatakan mengikut kepakaran dan kemahiran tabit yang mengendalikan sesebuah rawatan tersebut. Peranan herba yang bersifat panas dan dipercayai mampu mengeluarkan angin dalam tubuh badan dijadikan bahan terpenting dalam kaedah perubatan tradisi masyarakat Bajau Sama' Tuaran. Kepercayaan terhadap elemen mantera yang disadurkan bersama herba bagi merawat penyakit membuktikan bahawa masyarakat ini masih berpegang teguh kepada konsep folk medicine atau folk belief. Masyarakat Bajau Sama' yang mendiami kawasan pesisir pantai dan dikelilingi hutan membolehkan mereka melestarikan alam dalam konteks amalan kesihatan harian.

Peranan golongan pengamal perubatan tradisional yang arif dengan amalan tradisi dan ilmu perubatan telah menggambarkan kepentingan mereka dalam melancarkan segala urusan tugas harian sesama masyarakatnya. Walaupun kini rawatan moden mendapat tempat dalam aspek amalan kesihatan, alternatif rawatan tradisional juga tidak dikesampingkan. Hal ini demikian kerana konsep kepercayaan mereka terhadap perubatan cara tradisi yang sekian lama diamalkan secara warisan telah membuktikan fungsi rawatan tradisi lebih berkesan dan sesetengah penyakit yang tidak dapat didiagnosis mengikut cara moden, maka di situlah rawatan tradisi akan dipraktikkan bersama. Rawatan tradisi yang lebih mudah dipraktikkan dengan hanya meminum air rebusan dan sapuan ubatan kampung yang dihasilkan lebih mudah, cepat dan berkesan. Walaupun begitu, permasalahan yang timbul dalam rawatan tradisi ini apabila ubat yang dihasilkan atau herba tidak diuji atau diukur secara klinikal. Oleh itu, cadangan untuk melestarikan khazanah perubatan tradisi Bajau Sama' Tuaran ini perlu dikomersialkan menjadi salah satu bentuk ubat yang diuji dalam makmal, sekali gus dimanfaatkan oleh seluruh lapisan masyarakat berkenaan herba-herba yang digunakan dalam penghasilan perubatan dalam tingkat teknologi masa kini. 


\section{BIBLIOGRAFI}

Ahmad Faisal Abdul Hamid \& Nurul Wahidah binti Fauzi. (2012). Perubatan Melayu tradisional: Kitab Tibb Pontianak. Jurnal Al-Tamaddun, Vol. 7 (1): pp. 149-162.

Arena Wati. (1978). Dusun satu tinjauan dalam konteks kepercayaan, kultus dan hukum adat di Sabah. Kota Kinabalu: Yayasan Sabah.

Felipe Landa Jocano. (2003). Folk medicine in a Philippine Municipality. Philippines: Punlad Research House.

Hanafi Hussin. (2003). Bobohizan dan peranannya di kalangan masyarakat Kadazan Daerah Penampang, Sabah. Jurnal Jati, Bil. 8, Disember.

Hanafi Husin. (2005). Ritual padi komuniti Kadazan, Dataran Penampang Sabah. Jurnal Jati, Bil. 10, Disember.

Haliza Mohd. Riji. (2000). Prinsip dan amalan dalam perubatan Melayu. Kuala Lumpur: Universiti Malaya.

Haron Daud. (2004). Ulit Mayang kumpulan mantera Melayu. Kuala Lumpur: Dewan Bahasa dan Pusaka.

Haron Daud. (2009). Mantera dan unsur luar biasa dalam masyarakat Melayu. Pulau Pinang: Universiti Sains Malaysia.

Heru Setya Puji Saputra. (2007). Memuja mantra. Jakarta: Lkis Yogyakarta.

Jasman Bandar. (2015). Konsep mantera dalam masyarakat Bajau di Kampung Mapan-Mapan, Pitas Sabah. Kota Kinabalu: Universiti Malaysia Sabah. (Tesis sarjana yang belum diterbitkan)

Minah Sintian. (2012). Mantera atau rinait Kadazandusun: Tinjauan dalam aspek pengamal dan fungsinya dalam kehidupan - Kertas Kerja. Persidangan Simposium Bahasa dan Budaya Iban dan Folklor Borneo/ Kalimantan. Perak: Universiti Pendidikan Sultan Idris. Hlm. 121-142.

Mohd. Taib Osman. (1982). Bunga rampai kebudayaan Melayu. Kuala Lumpur: Dewan Bahasa dan Pustaka.

Normadiah Nassir \& Low Kok On. (2015). Penggunaan tumbuh-tumbuhan dalam pengubatan tradisonal etnik Murut Tahol di Sabah: Penelitian terhadap unsur kearifan tempatan. Jurnal Gendang Alam, Jilid 5.

Rogayah A.Hamid, Mariyam Salim. (2007). Pandangan semesta Melayu mantera. Kuala Lumpur: Dewan Bahasa dan Pustaka.

Saidatul Nornis. (1999). Mantera: Satu penelitian awal dalam kalangan petani Bajau. Jumal Kinabalu, Vol.V, hlm. 51-82.

Wan Hashim Wan Teh \& Ismail Hamid. (1998). Nilai budaya masyarakat desa. Kuala Lumpur: Dewan Bahasa dan Pustaka. 


\section{Temu bual}

Alis bin Sepok, 16 April 2017, Kampung Sungai Damit, Tuaran, Sabah.

Azmil bin Akim, 8 April 2017, Kampung Sungai Damit, Tuaran, Sabah.

Temiah binti Amat, 11 Mac 2017, Kampung Sungai Damit, Tuaran, Sabah.

Liadin@Yus bin Rajin, 29 Disember 2016, Kampung Tembiluk, Mengkabong, Sabah.

Zainah binti Alun, 28 Disember 2016, Kampung Suang Perumahan, Mengkabong, Sabah.

Senah binti Bidin, 25 Ogos 2016, Kampung Sungai Damit, Tuaran, Sabah.

Saidah binti Remis, 25 Ogos 2016, Kampung Sungai Damit, Tuaran, Sabah.

Madil bin Akim, 25 Ogos 2016, Kampung Sungai Damit, Tuaran, Sabah.

Abd Adis bin Sepok, 8 April 2016, Kampung Sungai Damit, Tuaran, Sabah.

Anna binti Atun, 3 Mac 2015 dan 27 April 2015, Kampung Sungai Damit, Tuaran, Sabah. 
